\title{
Campus Teaching Awards: 2019-2020 Academic Year
}

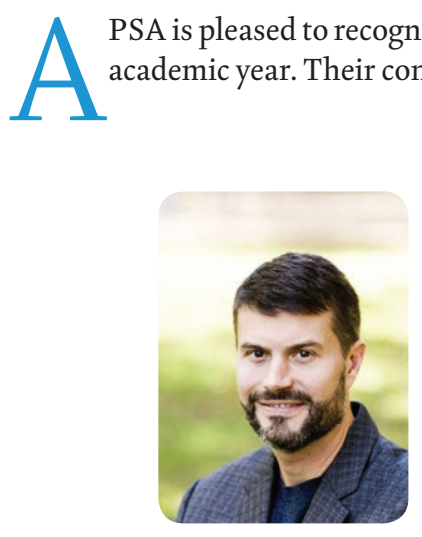

David Cunningham

University of Maryland, College Park 2020 Excellence in Mentorship Award

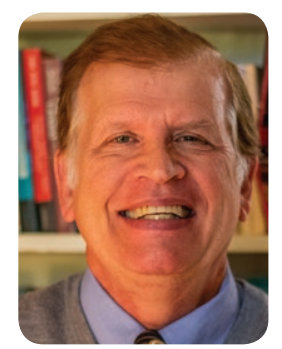

Fletcher McClellan

Elizabethtown College Kreider Prize for Teaching Excellence

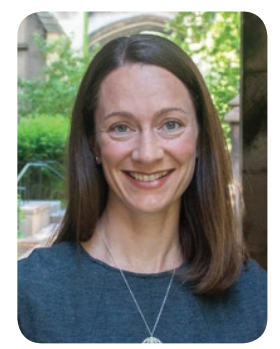

Felicity Vabulas

Pepperdine University Howard A. White Award for Teaching Excellence (non-tenured category)

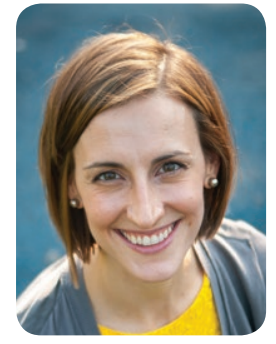

Rebecca Glazier

University of Arkansas at Little Rock University of Arkansas at Little Rock Student Government Association Faculty Appreciation Award

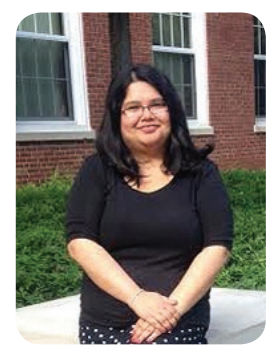

Deepa Prakash

DePauw University United Methodist Exemplary Teaching Award 2020

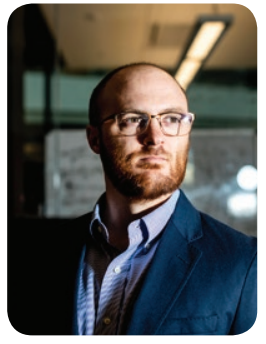

Justin Haner Northeastern University College of Social Sciences and Humanities 2019-2020 Outstanding Teaching Award

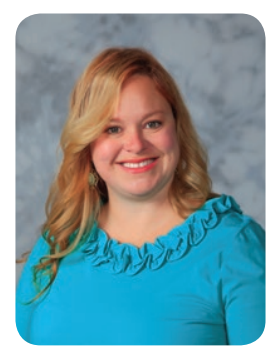

Jennie Sweet-Cushman Chatham University Buhl Professorship

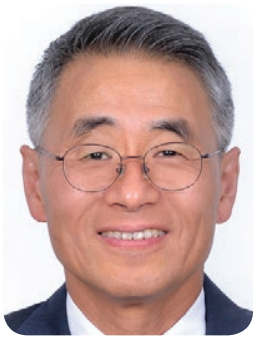

T.Y.Wang Illinois State University University Professor

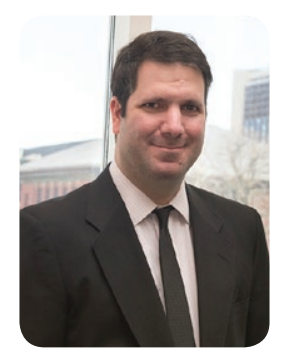

L.J Zigerell

Illinois State University Pi Sigma Alpha Excellence in Teaching Award and the Hibbert R. Roberts Teaching Excellence Recognition Award 